\title{
Down syndrome: a risk factor for malocclusion severity?
}

\section{Leandro Silva MARQUES(a) Carlos Eduardo Pinto ALCÂNTARA ${ }^{(\text {b) }}$ Luciano José PEREIRA ${ }^{(c)}$ Maria Letícia RAMOS-JORGE(a)}

(a) Universidade Federal dos Vales do Jequitinhonha e Mucuri - UFVJM, School of Biologic and Health Sciences, Department of Dentistry, Diamantina, MG, Brazil.

(b) Universidade Federal de Juiz de Fora UFJF, Department of Dentistry, Governador Valadares, MG, Brazil.

(c) Universidade Federal de Lavras - UFLA, Department of Health Sciences, Human Physiology Area, Lavras, MG, Brazil.

\section{Corresponding Author:}

Leandro Silva Marques

E-mail: Ismarques.prof@gmail.com

DOI: 10.1590/1807-3107BOR-2015.vol29.0044

Submitted: Jul 09, 2014

Accepted for publication: Dec 10, 2014

Last revision: Feb 02, 2015
Abstract: The aims of the present study were to compare aspects related to malocclusion between individuals with Down syndrome (DS) and a control group, establish malocclusion severity, and identify determinant factors. A total of 120 individuals (60 with DS and 60 with no physical or mental impairment), were included in the study. Data were collected through interviews, analyses of the medical charts, and oral examinations. The criteria of the Dental Aesthetic Index were used for the diagnosis of malocclusion. Chi-square test $(p \leq 0.05)$ and multivariate logistic regression were used for comparisons between the two groups and to determine the association between the dependent (malocclusion severity) and independent variables. Statistically significant differences were found between the two groups for the following variables: missing teeth, diastema, overjet, mandibular protrusion, anterior open bite, posterior crossbite, facial type, lip incompetence, and Angle classification. DS, a history of premature birth, and long face pattern were found to be associated with malocclusion severity. Individuals with DS exhibited more occlusal problems than those in the control group.

Keywords: Malocclusion; Down Syndrome; Orthodontics.

\section{Introduction}

Down syndrome (DS), also known as Trisomy 21, is the most common chromosomal disorder in humans, affecting 1-2 individuals out of every 1000 live births. ${ }^{1,2,3}$ Patients with this syndrome exhibit cognitive impairment as well as bone growth disorders and generalized muscle hypotonia. ${ }^{4,5}$ Moreover, oral health problems, such as inadequate oral hygiene, periodontal disease, caries, malocclusion, and tooth loss, are more prevalent in this group of individuals than in the general population. ${ }^{67,7,9}$ Malocclusion, in particular, exerts a considerable negative impact on the quality of life, causing problems related to the performance of daily activities, such as speech, swallowing, and chewing, and discrimination based on physical appearance. ${ }^{10,11}$

Patients with DS exhibit alterations such as an abnormal positioning of the tongue, craniofacial deformities (reduction in maxilla and mandible size, and narrow oropharynx), dental alterations (number and size of teeth), and muscle disorders. ${ }^{12,13,14}$ All these factors contribute toward the development of transversal and vertical alterations in the occlusion, such 
as anterior open bite, posterior or anterior crossbite, and the proclination of the anterior teeth. ${ }^{2,3}$

The prevalence of malocclusion and associated factors have been assessed in individuals with DS, 8,12,13 However, a critical reading of the literature reveals that there is a gap in knowledge concerning the determinant factors associated with the malocclusion establishment and severity. Many studies have failed to address certain individual, social, and behavioral aspects, such as age, birth weight, a history of premature birth, breathing pattern, and facial type. ${ }^{5,14,15}$ Moreover, methodological limitations, including insufficient sample size, inadequate data acquisition instruments, study designs with various sources of bias, and the use of only descriptive and comparative statistical analyses, have been encountered in the past. Thus, studies that can provide evidence with greater scientific weightage are of particular importance for the development of public policies aimed at preventive strategies and oral health promotion.

The aims of the present study were to compare aspects related to malocclusion between individuals with DS and a control group, establish malocclusion severity, and identify the determinant factors.

\section{Methodology}

The present study involved a sample made up of 120 individuals; 60 with DS ( 37 males and 23 females, average age of 14.73 years) and 60 with no physical or mental impairment but affected by different types of malocclusion (control group: 19 males and 41 females, average age of 12.18 years). The patients in the control group were randomly selected from individuals awaiting orthodontic treatment in the Course of Orthodontics specialization at the School of Dentistry in Itaúna, Brazil. Only those individuals who had not yet been submitted to orthodontic intervention were included in the study.

Data were collected through interviews, assessments of medical charts for the confirmatory diagnosis of DS, and oral examinations. Information pertaining to age, gender, mother's schooling, weight, and a history of premature birth were collected from children's mothers during the interview. Oral examinations were performed by an orthodontist. Prior to the assessment and diagnosis of malocclusion based on the criteria of the Dental Aesthetic Index (DAI), the orthodontist participated in a calibration exercise involving 12 individuals who did not belong to the main study and achieved high agreement values (maximal and minimal kappa values of 1.00 and 0.81 , respectively). The DAI provides four outcome possibilities: mild malocclusion or absence of abnormality, for which treatment is not necessary (DAI $\leq 25)$; defined malocclusion, for which treatment is elective (DAI = 26-30); severe malocclusion, for which treatment is highly desirable (DAI $=31-35)$; and very severe or debilitating malocclusion, for which treatment is fundamental (DAI $\geq 36$ ). ${ }^{16}$ Because all participants exhibited some type of malocclusion, the DAI score was dichotomized as moderate $(\mathrm{DAI} \leq 30)$ and severe (DAI > 30) malocclusion. Malocclusions were clinically categorized as Class I, Class II, or Class III, based on the Angle classification. During the clinical examination, posterior crossbite, facial type, and dentition (mixed or permanent) were also determined.

A lip competence examination was performed based on the method described by Ballard, ${ }^{17}$ the mandible was in the physiological resting posture and lips were in the juxtaposition (sealed) with no contraction of the orbicular muscles of the mouth or mentalis. Lip incompetence was recorded when the individual required vigorous contractions of the orbicular muscles of the mouth and mentalis to achieve a lip seal. In children, lip incompetence and breathing patterns (nasal or mouth) were assessed during the clinical examination and by interviewing the mothers when the child was not aware of being observed, thereby revealing the inherent behavior.

Data analysis was performed using the Statistical Package for Social Sciences (SPSS for Windows, version 17.0, SPSS Inc., Chicago, USA) and included frequency distribution and association tests. Associations between the dependent (malocclusion severity) and independent variables (gender, age, birth weight, a history of premature birth, mother's schooling, breathing pattern, dentition type, and facial type) were determined using the chi-square test $(p \leq 0.05)$. Variables with a $p$-value of $\leq 0.20$ were incorporated into the multivariate logistic regression model (forward stepwise procedure). The study was approved by the Ethics Committee with the protocol number 
0004.0.380.000-09. Parents/guardians signed the terms of informed consent authorizing their child's participation in the study.

\section{Results}

Individuals with DS had more number of missing teeth and a greater occurrence of mandibular protrusion, anterior open bite $(\mathrm{mm})$, posterior crossbite, and lip incompetence. As shown in Table 1, individuals in the control group had a greater occurrence of diastema ( $\geq 2 \mathrm{~mm}$ ) and overjet $(\geq 4 \mathrm{~mm})$. Differences were also found with regard to facial type and Angle classification between the two groups. Short face pattern and Angle Class III malocclusion were more frequent among the individuals with DS, whereas long face pattern and Angle Class II malocclusion were more frequent among the individuals in the control group (Table 1).

Malocclusion severity was greater among the individuals with DS than among those in the control group ( $p=0.028$ ). Considering individual, social, and behavioral factors, there was a greater frequency of severe malocclusion among individuals aged $>10$ years and among those with a history of premature birth, lip incompetence, mouth breathing pattern, and long face pattern (Table 2). After the adjustment of the model, logistic regression revealed that DS, a history of premature birth, and facial type (long face) were associated with a greater malocclusion severity (Table $3)$, regardless of the age or gender.

\section{Discussion}

The majority of studies assessing factors associated with malocclusion in individuals with DS only provide descriptive and comparative statistical analyses and fail to determine malocclusion severity in these individuals. ${ }^{8,12,13}$ For this reason, the control group was comprised of individuals without DS and seeking orthodontic treatment, rather than individuals unaffected by malocclusion or those with similar malocclusions.

The most frequent malocclusions among the individuals with DS were mandibular protrusion, anterior open bite, and posterior crossbite. These findings confirm the results of previous studies reporting high prevalence values for malocclusions stemming from vertical and transversal occlusal alterations. ${ }^{2,3,14,18}$ Such alterations are associated with insufficient bone development, orofacial muscle hypotonia, and the positioning of the tongue., , 14,19,20 $^{2}$ Muscle hypotonia associated with a reduced volume of the oral cavity and characterized by a deep, atresic palate may lead to a tendency toward habitually projecting the tongue against the teeth or outside the mouth. ${ }^{5,18,21}$ Abnormal function and the position of the tongue can affect tooth eruption causing anterior open bite, tooth alignment, and the arch shape. ${ }^{12,22}$ However, these variables were not assessed in the present study. A pervious study ${ }^{23}$ using the same control group identified that patients with cerebral palsy also had more anterior open bite, suggesting that muscle impairment in both disorders contributes toward malocclusion.

Patients with DS generally have a short face pattern and a reduced development of the middle third of the face, resulting in a Class III occlusal relation. ${ }^{8,24,25}$ The present study corroborates these findings. However, patients with long face pattern also exhibited a greater chance of developing severe malocclusion. The long face pattern is associated with muscle hypotonia and a tendency toward the downward rotatation of the mandible, favoring the development of Angle Class II malocclusion. ${ }^{26}$

Altered breathing pattern is strongly associated with malocclusion. ${ }^{20}$ Góis et al. ${ }^{27}$ found that children with mouth breathing patterns have a 10 -fold greater chance of exhibiting malocclusion compared with those with nasal breathing patterns. In the present study, mouth breathing was associated with both malocclusion prevalence and severity because $85 \%$ of the mouth breathing patients exhibited severe malocclusion. In the logistic regression analysis, however, this variable did not adjust to the model because most individuals with DS also exhibited mouth breathing patterns. Mouth breathing patterns are more frequent due to orofacial muscle hypotonia and an absence of the lip seal. ${ }^{12}$

Children with a history of premature birth had a greater chance of developing severe malocclusion. A recent systematic review reported scientific evidence for altered palatal morphology among children born prematurely but with contradictory findings. ${ }^{28}$ However, 
Down syndrome: a risk factor for malocclusion severity?

Table 1. Univariate analysis considering aspects related to malocclusion in the Down syndrome group and control group without mental impairment.

\begin{tabular}{|c|c|c|c|}
\hline & \multicolumn{2}{|c|}{ Group } & \multirow[b]{2}{*}{$p^{*}$} \\
\hline & Control n (\%) & Down syndrome n (\%) & \\
\hline \multicolumn{4}{|l|}{ Missing teeth } \\
\hline None & $59(60.2)$ & $39(39.8)$ & $<0.001$ \\
\hline At least one & $1(4.5)$ & $21(95.5)$ & \\
\hline \multicolumn{4}{|l|}{ Crowding } \\
\hline None & $31(44.9)$ & $38(55.1)$ & 0.196 \\
\hline 1 or 2 segments & $29(56.9)$ & $22(43.1)$ & \\
\hline \multicolumn{4}{|l|}{ Spacing } \\
\hline None & $34(48.6)$ & $36(51.4)$ & 0.711 \\
\hline 1 or 2 segments & $26(52.0)$ & $24(48.0)$ & \\
\hline \multicolumn{4}{|l|}{ Diastema (mm) } \\
\hline$<2$ & $47(46.1)$ & $55(53.9)$ & 0.041 \\
\hline$\geq 2$ & $13(72.2)$ & $5(27.8)$ & \\
\hline \multicolumn{4}{|c|}{ Maxillary irregularity (mm) } \\
\hline$<2$ & $48(50.0)$ & $48(50.0)$ & 1.000 \\
\hline$\geq 2$ & $12(50.0)$ & $12(50.0)$ & \\
\hline \multicolumn{4}{|c|}{ Mandibular Irregularity (mm) } \\
\hline$<2$ & $50(48.1)$ & $54(51.9)$ & 0.283 \\
\hline$\geq 2$ & $10(62.5)$ & $6(37.5)$ & \\
\hline \multicolumn{4}{|l|}{ Overjet (mm) } \\
\hline$<4$ & $46(44.2)$ & $58(55.8)$ & 0.001 \\
\hline$\geq 4$ & $14(87.5)$ & $2(12.5)$ & \\
\hline \multicolumn{4}{|c|}{ Mandibular protrusion } \\
\hline No & $59(56.7)$ & $45(43.3)$ & $<0.001$ \\
\hline Yes & $1(6.3)$ & $15(93.8)$ & \\
\hline \multicolumn{4}{|c|}{ Anterior open bite (mm) } \\
\hline$<2$ & $57(56.4)$ & $44(43.6)$ & 0.001 \\
\hline$\geq 2$ & $3(15.8)$ & $16(84.2)$ & \\
\hline \multicolumn{4}{|l|}{ Posterior crossbite } \\
\hline Absent & $53(65.4)$ & $28(34.6)$ & $<0.001$ \\
\hline Present & 7 (17.9) & $32(82.1)$ & \\
\hline \multicolumn{4}{|l|}{ Facial type } \\
\hline Short face & $1(4.2)$ & $23(95.8)$ & $<0.001$ \\
\hline Average & $45(58.4)$ & $32(41.6)$ & \\
\hline Long face & $14(73.7)$ & $5(26.3)$ & \\
\hline \multicolumn{4}{|l|}{ Lip incompetence } \\
\hline No & $44(58.7)$ & 31 (41.3) & 0.014 \\
\hline Yes & $16(35.6)$ & $29(64.4)$ & \\
\hline \multicolumn{4}{|l|}{ Angle classification } \\
\hline Class I & $31(70.5)$ & $13(29.5)$ & $<0.001$ \\
\hline Class II & $25(61.0)$ & $16(39.0)$ & \\
\hline Class III & $4(11.4)$ & $31(88.6)$ & \\
\hline \multicolumn{4}{|l|}{ Dentition } \\
\hline Mixed & $44(55.0)$ & $36(45.0)$ & 0.121 \\
\hline Permanent & $16(40.0)$ & $24(60.0)$ & \\
\hline
\end{tabular}

${ }^{*}$ Chi-square test $(p \leq 0.05)$ 
Table 2. Univariate analysis of association between malocclusion severity and individual, social, and behavioral variables.

\begin{tabular}{|c|c|c|c|}
\hline & \multicolumn{2}{|c|}{ Malocclusion severity (DAI) } & \multirow[b]{2}{*}{$P^{*}$} \\
\hline & Moderate & Severe & \\
\hline \multicolumn{4}{|l|}{ Group } \\
\hline Control & 35 (58.3) & $25(41.7)$ & 0.028 \\
\hline Down syndrome & $23(38.3)$ & $37(61.7)$ & \\
\hline \multicolumn{4}{|l|}{ Sex } \\
\hline Male & $23(41.1)$ & $33(58.9)$ & 0.136 \\
\hline Female & $35(54.7)$ & $29(45.3)$ & \\
\hline \multicolumn{4}{|l|}{ Age (y) } \\
\hline$\leq 10$ & $37(59.7)$ & $25(40.3)$ & 0.010 \\
\hline$>10$ & $21(36.2)$ & $37(63.8)$ & \\
\hline \multicolumn{4}{|l|}{ Birth weight (g) } \\
\hline$\geq 2500$ & $29(44.6)$ & $36(55.4)$ & 0.282 \\
\hline$<2500$ & $9(60.0)$ & $6(40.0)$ & \\
\hline \multicolumn{4}{|l|}{ Premature birth } \\
\hline No & $52(52.0)$ & $48(48.0)$ & 0.030 \\
\hline Yes & $4(23.5)$ & $13(76.5)$ & \\
\hline \multicolumn{4}{|c|}{ Mother's schooling (y) } \\
\hline$>4$ & 30 (46.9) & $34(53.1)$ & 0.733 \\
\hline$\leq 4$ & $28(50.0)$ & $28(50.0)$ & \\
\hline \multicolumn{4}{|l|}{ Breathing } \\
\hline Nasal & $55(55.0)$ & $45(45.0)$ & 0.001 \\
\hline Mouth & $3(15.0)$ & $17(85.0)$ & \\
\hline \multicolumn{4}{|l|}{ Lip incompetence } \\
\hline No & $43(57.3)$ & $32(42.7)$ & 0.011 \\
\hline Yes & 15 (33.3) & $30(66.7)$ & \\
\hline \multicolumn{4}{|l|}{ Dentition } \\
\hline Mixed & $43(53.8)$ & $37(46.3)$ & 0.093 \\
\hline Permanent & 15 (37.5) & $25(62.5)$ & \\
\hline \multicolumn{4}{|l|}{ Facial type } \\
\hline Short face & $10(41.7)$ & $14(58.3)$ & 0.014 \\
\hline Average & $44(57.1)$ & $33(42.9)$ & \\
\hline Long face & $4(21.1)$ & 15 (78.9) & \\
\hline
\end{tabular}

${ }^{*}$ Chi-square test $(p \leq 0.05)$

another well-designed controlled study suggested that prematurely born children exhibit more malocclusion characteristics and have greater requirement for orthodontic treatment than full-term born children. ${ }^{29}$ These findings suggest that preterm children should be more closely monitored by orthodontists, who should be aware of the tendency toward severe malocclusion and the orthodontic treatment needs among such children. ${ }^{29}$ Further longitudinal studies are required to address the issue as to whether premature births result in dentofacial alterations.
A recent study used the DAI to determine the degree of malocclusion in patients with DS and found that $83.2 \%$ of them had severe and very severe malocclusion. ${ }^{30}$ In the present study, after adjusting for all potential variables related to malocclusion severity, it was found that DS is a risk factor for severe malocclusion. Therefore, the assessment and monitoring of individual, oral, social, and behavioral aspects is of considerable clinical importance to orthodontists. This is particularly true with regard to individuals with DS who receive little assistance 
Down syndrome: a risk factor for malocclusion severity?

Table 3. Univariate and multivariate logistic regression analyses considering associations between malocclusion severity and independent variables.

\begin{tabular}{|c|c|c|c|c|}
\hline & OR Non adjusted $(95 \% \mathrm{Cl})$ & $P$ & OR adjusted $(95 \% \mathrm{Cl})$ & $P$ \\
\hline \multicolumn{5}{|l|}{ Group } \\
\hline Control & 1.00 & & 1.00 & \\
\hline Down syndrome & $2.25(1.1-4.7)$ & 0.029 & $4.24(1.3-13.4)$ & 0.014 \\
\hline \multicolumn{5}{|l|}{ Age (y) } \\
\hline$\leq 10$ & 1.00 & & 1.00 & \\
\hline$>10$ & $2.61(1.2-5.4)$ & 0.011 & $2.69(0.9-8.4)$ & 0.086 \\
\hline \multicolumn{5}{|l|}{ Gender } \\
\hline Male & 1.00 & & 1.00 & \\
\hline Female & $0.58(0.3-1.2)$ & 0.138 & $0.58(0.2-1.4)$ & 0.233 \\
\hline \multicolumn{5}{|l|}{ Premature birth } \\
\hline No & 1.00 & & 1.00 & \\
\hline Yes & $3.52(1.1-11.5)$ & 0.038 & $4.11(1.1-15.9)$ & 0.041 \\
\hline \multicolumn{5}{|l|}{ Facial type } \\
\hline Short face & 1.00 & & 1.00 & \\
\hline Average & $0.54(0.2-1.3)$ & 0.188 & $2.15(0.6-7.4)$ & 0.226 \\
\hline Long face & $2.68(0.7-10.5)$ & 0.158 & $13.1(2.2-76.1)$ & 0.004 \\
\hline \multicolumn{5}{|l|}{ Breathing } \\
\hline Nasal & 1.00 & & & \\
\hline Mouth & $6.93(1.9-25.1)$ & 0.003 & -- & \\
\hline \multicolumn{5}{|l|}{ Lip incompetence } \\
\hline No & 1.00 & 0.012 & --- & \\
\hline Yes & $2.69(1.2-5.8)$ & & & \\
\hline \multicolumn{5}{|l|}{ Dentition } \\
\hline Mixed & 1.00 & & 1.00 & \\
\hline Permanent & $1.94(0.9-4.2)$ & 0.095 & $1.08(0.3-3.5)$ & 0.898 \\
\hline
\end{tabular}

and the professionals who treat such individuals are most often ill prepared to offer better care. Thus, the treatment of malocclusion for individuals with DS can lead to a considerable improvement in their quality of life..$^{18,20}$

\section{Conclusions}

Vertical and transversal alterations in the occlusion, such as mandibular protrusion, anterior open bite, and posterior crossbite were significantly more frequent among the individuals with DS than those in the control group. The determinant factors associated with malocclusion severity were DS, a history of premature birth, and long face pattern.

\section{Acknowledgments}

The authors are grateful to the Capes (Coordenação de Aperfeiçoamento de Pessoal de Nível Superior) and FAPEMIG (Fundação de Amparo à Pesquisa do Estado de Minas Gerais) for their financial support.

\section{References}

1. Dzurova D, Pikhart H. Down syndrome, paternal age and education: comparison of California and the Czech Republic. BMC Public Health. 2005 Jun 17;5:69.

2. Venail F, Gardiner Q, Mondain M. ENT and speech disorders in children with Down's syndrome: an overview of pathophysiology, clinical features, treatments, and current management. Clin Pediatr (Phila). 2004 Nov-Dec;43(9):783-91.
3. Kaye PL, Fiske J, Bower EJ, Newton JT, Fenlon M. Views and experiences of parents and siblings of adults with DownSyndrome regarding oral healthcare: a qualitative and quantitative study. $\mathrm{Br}$ Dent J. 2005 May 14;198(9):571-8, discussion 559.

4. Suri S, Tompson BD, Cornfoot L. Cranial base, maxillary and mandibular morphology in Down syndrome. Angle Orthod. 2010 Sep;80(5):861-9. DOI: 10.2319/111709-650. 
5. Korbmacher H, Limbrock J, Kahl-Nieke B. Orofacial development in children with Down's syndrome 12 years after early intervention with a stimulating plate. J Orofac Orthop. 2004 Jan;65(1):60-73.

6. Khocht A, Janal M, Turner B. Periodontal health in Down syndrome: contributions of mental disability, personal, and professional dental care. Spec Care Dentist. 2010 May-Jun;30(3):118-23. DOI: 10.1111/j.1754-4505.2010.00134.x.

7. Amaral Loureiro AC, Oliveira Costa F, Eustáquio da Costa J. The impact of periodontal disease on the quality of life of individuals with Down syndrome. Downs Syndr Res Pract. 2007 Jul;12(1):50-4.

8. Winter K, Baccaglini L, Tomar S. A review of malocclusion among individuals with mental and physical disabilities. Spec Care Dentist. 2008 Jan-Feb;28(1):19-26. DOI: 10.1111/j.1754-4505.2008.00005.x.

9. Anders PL, Davis EL. Oral health of patients with intellectual disabilities: a systematic review. Spec Care Dentist. 2010 May-Jun;30(3):110-7. DOI: 10.1111/j.1754-4505.2010.00136.x.

10. Stoel-Gammon C. Down syndrome phonology: developmental patterns and intervention strategies. Downs Syndr Res Pract. 2001 Oct;7(3):93-100.

11. Musich DR. Orthodontic intervention and patients with Down syndrome. Angle Orthod. 2006 Jul;76(4):734-5.

12. Oliveira AC, Pordeus IA, Torres CS, Martins MT, Paiva SM. Feeding and nonnutritive sucking habits and prevalence of open bite and crossbite in children/adolescents with Down syndrome. Angle Orthod. 2010 Jul;80(4):748-53. doi: 10.2319/072709-421.1.

13. Bäckman B, Grevér-Sjölander AC, Bengtsson K, Persson J, Johansson I. Children with Down syndrome: oral development and morphology after use of palatal plates between 6 and 48 months of age. Int J Paediatr Dent. 2007 Jan;17(1):19-28.

14. Quintanilla JS, Biedma BM, Rodríguez MQ, Mora MT, Cunqueiro MM, Pazos MA. Cephalometrics in children with Down's syndrome. Pediatr Radiol. 2002 Sep;32(9):635-43. Epub 2002 Apr 5.

15. Hennequin M, Allison PJ, VeyruneJL. Prevalence of oral health problems in a group of individuals with Down syndrome in France. Dev Med Child Neurol. 2000 Oct;42(10):691-8.

16. Jenny J, Cons NC. Establishing malocclusion severity levels on the Dental Aesthetic Index (DAI) scale. Aust Dent J. 1996 Feb;41(1):43-6.

17. Ballard CF. The effect of lip morphology on the incisors following treatment. Orthod Fr. 1969;40:181-95. French.

18. Oliveira AC, Paiva SM, Campos MR, Czeresnia D. Factors associated with malocclusions in children and adolescents with Down syndrome. Am J Orthod Dentofacial Orthop. 2008 Apr;133(4):489.e1-8. DOI: 10.1016/j.ajodo.2007.09.014.

19. Waldman HB, Perlman SP, Swerdloff M. Orthodontics and the population with special needs. Am J Orthod Dentofacial Orthop. 2000 Jul;118(1):14-7.

20. Oliveira AC, Paiva SM, Martins MT, Torres CS, Pordeus IA. Prevalence and determinant factors of malocclusion in children with special needs. Eur J Orthod. 2011 Aug;33(4):413-8. DOI: 10.1093/ejo/cjq094. Epub 2010 Oct 18.

21. Zavaglia V, Nori A, Mansour NM. Long term effects of the palatal plate therapy for the orofacial regulation in children with Down syndrome. J Clin Pediatr Dent. 2003 Fall;28(1):89-93.

22. Chawla HS, Suri S, Utreja A. Is tongue thrust that develops during orthodontic treatment an unrecognized potential road block? J Indian Soc Pedod Prev Dent. 2006 Jun;24(2):80-3.

23. Miamoto CB, Ramos-Jorge ML, Pereira LJ, Paiva SM, Pordeus IA, Marques LS. Severity of malocclusion in patients with cerebral palsy: determinant factors. Am J Orthod Dentofacial Orthop. 2010 Oct;138(4):394.e1-5; discussion 394-5. DOI: 10.1016/j.ajodo.2010.03.025.

24. Shyama M, al-Mutawa SA, Honkala S. Malocclusions and traumatic injuries in disabled schoolchildren and adolescents in Kuwait. Spec Care Dentist. 2001 May-Jun;21(3):104-8.

25. Alio JJ, Lorenzo J, Iglesias C. Cranial base growth in patients with Down syndrome: a longitudinal study. Am J Orthod Dentofacial Orthop. 2008 May;133(5):729-37. DOI: 10.1016/j.ajodo.2006.03.036.

26. Marques LS, Ramos-Jorge ML, Araujo MT, Bolognese AM. Class II Division 1 malocclusion with severe overbite: cephalometric evaluation of the effects of orthodontic treatment. World J Orthod. 2008 Winter;9(4):319-28.

27. Góis EG, Ribeiro-Júnior HC, Vale MP, Paiva SM, Serra-Negra JM, Ramos-Jorge ML, et al. Influence of nonnutritive sucking habits, breathing pattern and adenoid size on the development of malocclusion. Angle Orthod. 2008 Jul;78(4):647-54. DOI: 10.2319/0003-3219(2008)078[0647:IONSHB]2.0.CO;2.

28. Paulsson L, Bondemark L, Söderfeldt B. A systematic review of the consequences of premature birth on palatal morphology, dental occlusion, tooth-crown dimensions, and tooth maturity and eruption. Angle Orthod. 2004 Apr;74(2):269-79.

29. Paulsson L, Söderfeldt B, Bondemark L. Malocclusion traits and orthodontic treatment needs in prematurely born children. Angle Orthod. 2008 Sep;78(5):786-92. DOI: 10.2319/083007-402.1.

30. Abdul Rahim FS, Mohamed AM, Nor MM, Saub R. Malocclusion and orthodontic treatment need evaluated among subjects with Down syndrome using the Dental Aesthetic Index (DAI). Angle Orthod. 2014 Jul;84(4):600-6. 